\title{
SPATIAL ACCESSIBILITY AND REGIONAL ECONOMIC DEVELOPMENT WITHIN THE EUROPEAN UNION
}

\author{
Cezar Teclean ${ }^{102}$
}

https://doi.org/10.31410/itema.2018.266

\begin{abstract}
In this paper we propose to evaluate the role of spatial accessibility on the regional economic development in the European Union. The evaluation criterion of spatial accessibility is represented by interregional territorial connectivity given by the highways and high-speed railways infrastructures. In order to measure the territorial interconnectivity, we used the number of border territorial connections of each NUTS 2 region for highways and high-speed railways. In order to evaluate the regional economic development, we used the value of the regional GDP (gross domestic product). The space modeling of territorial accessibility, obtained by quantitative mapping of trans-regional interconnection, allowed the identification of areas with different levels of infrastructural equipment. The interpolation of the interregional connection with the regional GDP distribution allowed quantifying the impact of spatial accessibility on the regional economic development. The relevance of this approach is that, according to this model prepared, we will be able to identify the spaces what they need improving their interregional contacts, as a prerequisites for economic growth. In fact, the results of our research highlight the proposal of a space ranking of the infrastructural priorities, in order to homogenize the regional economic development, as a condition for increasing the economic and territorial connection on main land.
\end{abstract}

Keywords: spatial accessibility, highway infrastructure, high-speed railways infrastructure, regional economic development, European Union

\section{INTRODUCTION}

The economic and territorial cohesion represents a major scope of the durable development strategies of the European Union and regional economic development constitutes an essential condition for achieving this cohesion [1][2]. In this context, we will evaluate the contribution of space / territorial accessibility given by the highways and highspeed railways networks, as major impact factor for regional development. Our analysis highlights the determinant relationship between the interregional connection provided by the mentioned transport infrastructures and the level of regional economic development. The purpose of this paper is to issue a space model that would allow the identification of regions with infrastructural equipment deficit, for which improving the territorial interconnection superior level highways and high-speed railways would trigger regional economic development with effects in increasing economic and territorial conversion and cohesion.

\section{PROBLEM STATEMENT}

Space accessibility began to be perceived in the ' 80 s as an important factor which favors regional development within space economy research regarding gravitational development

\footnotetext{
102 Bucharest University of Economic Studies - Centre of International Business and Economics, Piața Romană 6, Bucharest, Romania
} 
models [3]. Later, territorial accessibility became an indispensable term pending studies of localization theories promoted in the new economic geography of the year's '90s-'2000 [4][5].

Together with the deepening of the integration process in the Single European Market, the space accessibility offered by transport networks has become a more and more connected concept to the sustainable development paradigm [6]. In this context, the promotion of the concept of sustainable accessibility circumscribes several epistemic dimensions: the integration of transport networks into territorial planning projects [7][8][9], sustainability of transport infrastructure projects [10][1], the investments contribution for expanding the transport networks [11][12]. Hensher et al. [13] and Condeço-Melhorado et al. [14] consider that territorial accessibility is a result of the interaction between transport networks and the space systems that serve it. Interregional connectivity given by the highways and high-speed railways networks is considered by Calatayud et al. [15] as the main vector of territorial cooperation that assures the regional integration dimension of the Union's internal market.

The accessibility assured by the transport infrastructures supports economic growth through a regional spill-over effect [16][17], but, at the same time, puts the European Community on the global orbit [18][19]. According to Hae [20] and Howel [21], the geography of transport networks is a landmark for regional economic reproduction and for community and global integration. The multiple effects generated by infrastructure distribution at the regional level are essential for increasing economic and territorial convergence and cohesion in the EU. [22][23]. In this respect, López et al. [24] has shown that the space accessibility impact over the economic and territorial cohesion increase is directly proportional with the volume of infrastructural interregional connection investments. Puga [25] and Scholz [26] underline the divergent effects of the infrastructure deficit in territorial cohesion: inter-regional development differences between accessible central areas and suburbs with accessibility deficiencies.

The rehabilitation of development gaps is the subject of European and national niche policies aimed at increasing territorial interconnectivity. The sufficiency or shortage of transport networks leads to segregated economic behaviors by both potential investors [24][16] and by decision-makers through the adoption of differentiated investment policies [27][28].

\section{RESEARCH METHODS}

The objective of the study is to identify regions with a lack of space accessibility, for which multiplication of interregional interconnection by highways and high-speed railways would contribute to regional GDP growth and economic and territorial cohesion. The research hypothesis claims that differentiated spatial accessibility due to inter-regional connectivity disconnections is one of the main factors responsible for the divergences of economic development within the European Union.

The investigation of the proposed theme implies the following steps:

- establishing indicators for assessing spatial accessibility and regional economic potential;

- drawing up regional accessibility and distribution maps of regional GDP using NUTS 2 regions in the U.E.;

- interpolation of spatial accessibility and regional GDP distribution \& interpreting the results;

- formulating proposals for extending trans-regional connections as a prerequisite for increasing economic and territorial cohesion in the EU. 
Indicators for assessing territorial accessibility and economic potential and their associated values are outlined in Table 1.

Table 1: Assessing criteria and measuring variables of spatial accessibility and economic potential

\begin{tabular}{|c|c|}
\hline $\begin{array}{l}\text { Evaluation } \\
\text { indicators }\end{array}$ & Proxy variables \\
\hline \multirow[b]{2}{*}{$\begin{array}{l}\text { Contiguous territorial } \\
\text { connection }\end{array}$} & Number of neighboring territorial connections on highways \\
\hline & $\begin{array}{c}\text { Number of neighboring territorial connections on } \\
\text { high-speed railways }\end{array}$ \\
\hline Economic potential & GDP by NUTS 2 regions \\
\hline
\end{tabular}

Source: Author's own representation and Eurostat (2016)

The neighboring connections of the NUTS 2 regions (i.e. the number of crossing points of the administrative boundaries of each region on highways and high-speed railways) were identified by observations on thematic profile maps and the regional GDP data were accessed from the Eurostat data base. The use of the mapping method allowed representation of the interconnected accessibility of the analyzed transport networks (Figure 1) and the regional GDP distribution (Figure 2).

Figure 1: Territorial connectivity given by the land transport networks

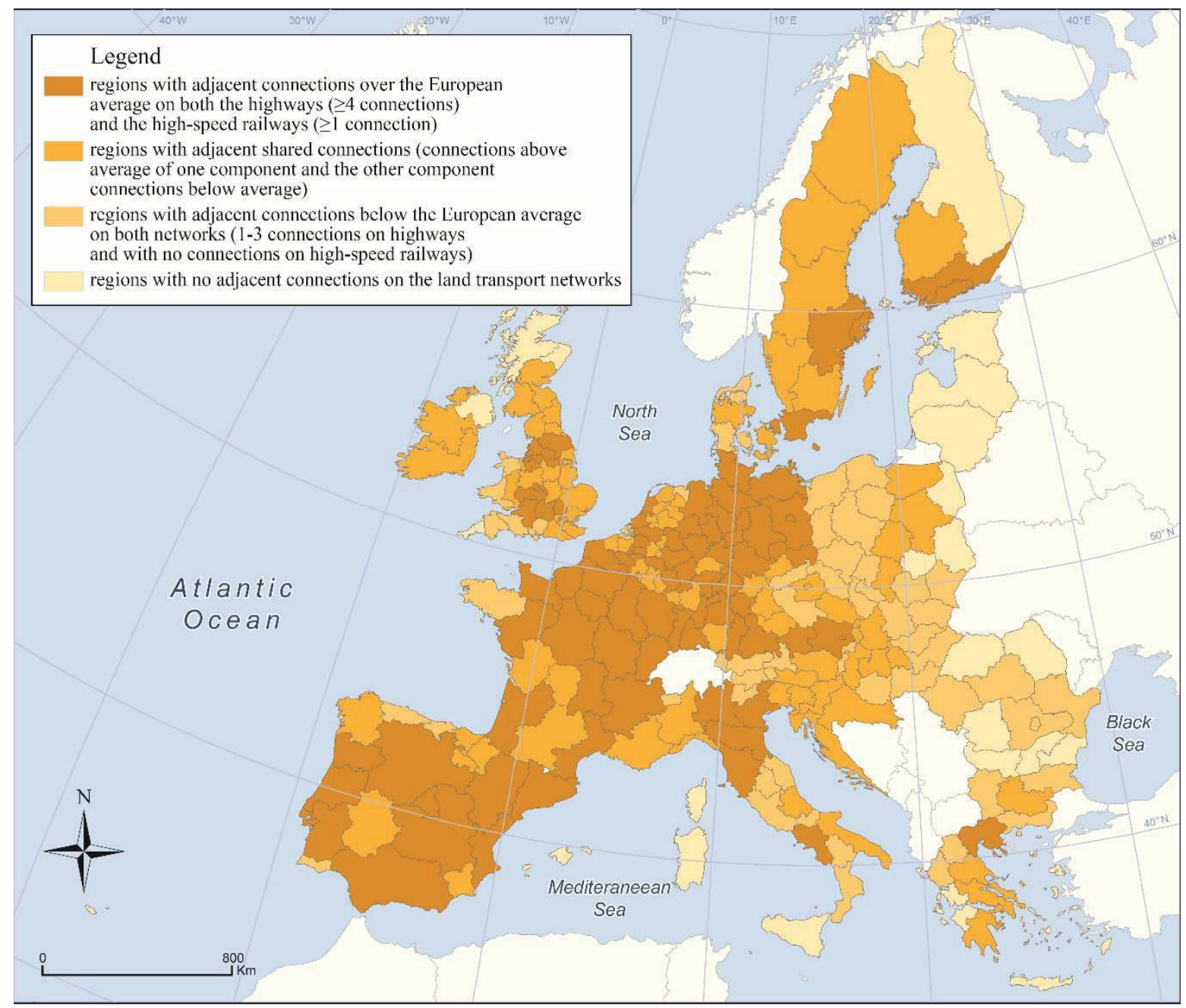

Source: Author's own representation 
Figure 2: Distribution of regional GDP in the European Union

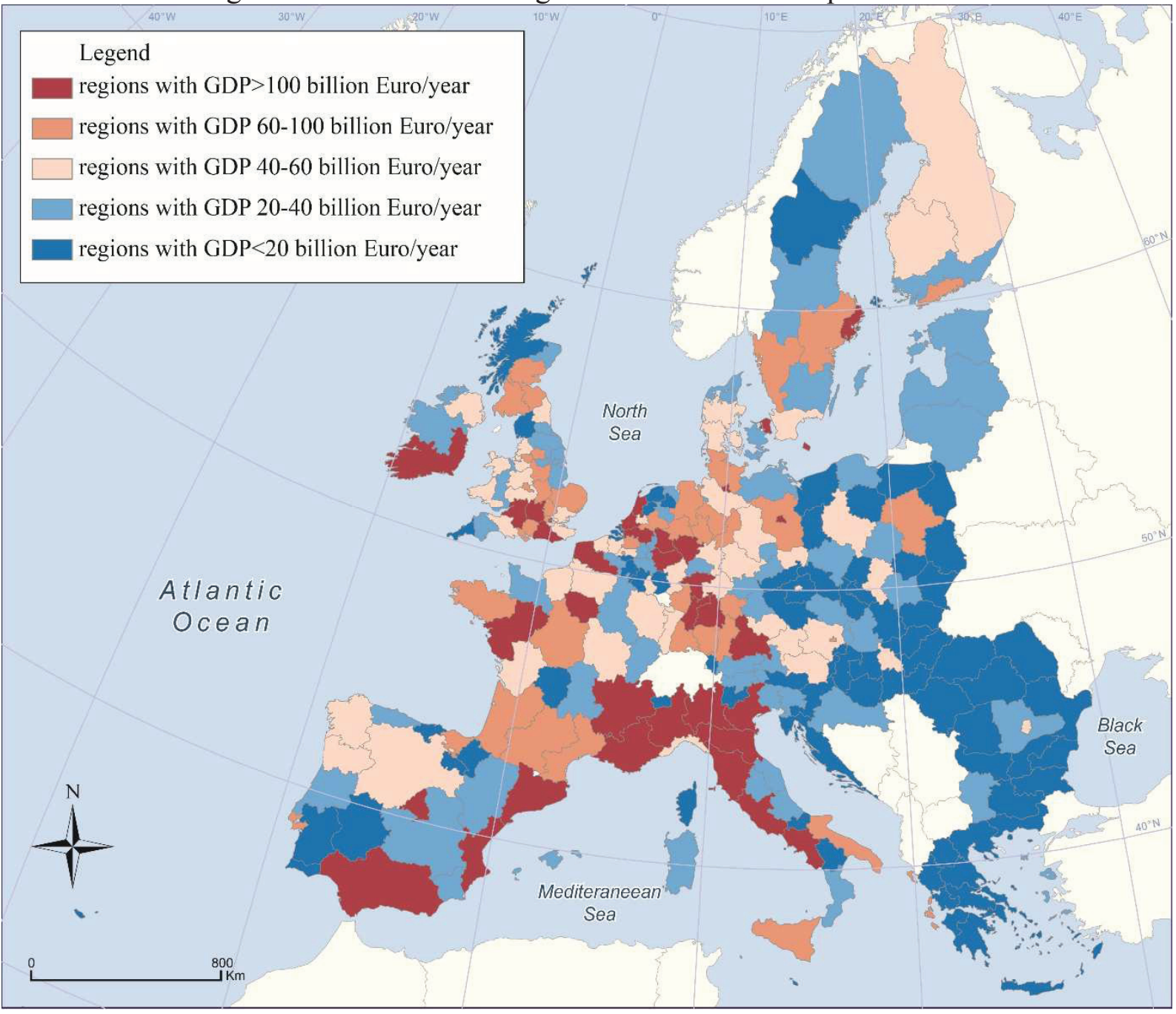

Source: Author's own representation using data from Eurostat (2016)

The interregional connectivity provided by terrestrial transport infrastructures (highways and high-speed railways networks) emphasizes, on the one hand, inter-regional differences in equipment with contact infrastructures and, on the other hand, points out compensatory effects between the two categories of terrestrial infrastructure. The spatial overlap of the interconnection facilities of the two networks homogenizes the European "photo" of space accessibility; interconnection alternatives are attenuated and facilitating regional economic growth in the EU.

Thus, compared to the 130 regions (38.3\% of the EU area) with a border connection level by highways below the European average (under 4 outer connections/ region) and 172 regions (62.2\% of the EU area) above-average high-speed railways connections (under 1 connection/ region), we have only 88 regions (34.4\% of the EU) with a territorial connection deficit on both infrastructure components. Per state, only 4 member states are composed only of territorially weakly connected territories (the Baltic republics and Romania, excluding Cyprus and Malta islands), compared to 6 states weakly connected by highways and 10 states with poor highspeed railways connection. These smaller discrepancies reveal a much weaker territorial connection divergence when cumulating the interconnection-territorial effects of the two terrestrial networks than in each of them separately. 
Therefore, their combined connectivity provides a more homogeneous spatial radiogram and implicitly a higher territorial cohesion over larger spaces. Well connected and serviced regions are more and more extensive in space and are found outside the nine trans-European routes. But at the same time, the isolation and exposure to territorial exclusion of the 88 regions and 4 states with dual infrastructure interconnection deficiency is more defined.

\section{FINDINGS}

On the scale of accessibility of both infrastructures, however, the old Europe, which is more endowed than the new Europe, is more clearly distinguished. On this evaluation background, the connectivity cleavage in the Central-Eastern Europe "new Europe" appears. Indeed, a very good Baltic-Adriatic dorsal link of good connectivity starts from the NE-SV diagonal of Poland (the Mazurian lakes - the Warsaw-Lodz-Upper Silesia region) and continues on a route connecting Moravia and the west of Slovakia with the regions of the basin of Vienna, and further through Slovenia, Croatia, northern Italy to the Adriatic. This dorsal is in sharp contrast with the western part of Poland, but especially with the eastern part, which together with the Baltic countries in the north and the regions of eastern Slovakia and eastern Hungary and further from Romania and Bulgaria form a true depression of poor connection and access. This phenomenon predictably overlaps a similar, albeit attenuated, spatial drawing of regional GDP distribution.

For Western Europe, the high regional GDP figures take into account to a large extent the existence of various favorable factors, such as the concentration of economic and financial centers in the Paris area, the London basin, the Frankfurt-Rhine ring, the Amsterdam-Brussels area, northern Italy, on the Spanish coast. In Central-Eastern Europe, in the absence of these economic strengths, GDP geography depends more on infrastructural equipment, a context similar to the good territorial connectivity overlooking the Polish dorsal.

In order to identify the regions for which the increase in territorial accessibility would have a major impact on economic growth, we used the spatial interpolating method of the territorial connectivity deficits (regions with interconnection levels below the European average) and the volume of regional GDP (regions with GDP below EURO 20 billion / year). Mapping the relation between the degree of territorial interconnection and the regional GDP reveals the segregation of lower GDP areas in two categories according to the level of accessibility deficit registered.

The two categories of identified areas (Figure 3) are, in fact, a hierarchy of the territorial interconnection priorities that Community and national decision-makers should consider in order to homogenize regional economic development:

- $1^{\text {st }}$ level priority areas are regions with a regional GDP below EURO 20 billion and no external connections on highways and high-speed railways: Baltic states, eastern Poland, northern and southwest Romania, northern Bulgaria, western Greece, northern Finland, the northern extreme of Scotland, Northern Ireland, the outskirts of the Cornwall peninsula.

- $2^{\text {nd }}$ level priority areas include regions with a regional GDP below EURO 20 billion and external connections below the Community average (less than 4 external links on highways and 0 high-speed railways connections); have a more ubiquitous distribution in the EU, occupying preponderant areas in Central Eastern Europe but also marginal areas in the West Europe. 
Figure 3: Spatial priorities for territorial interconnection in the European Union

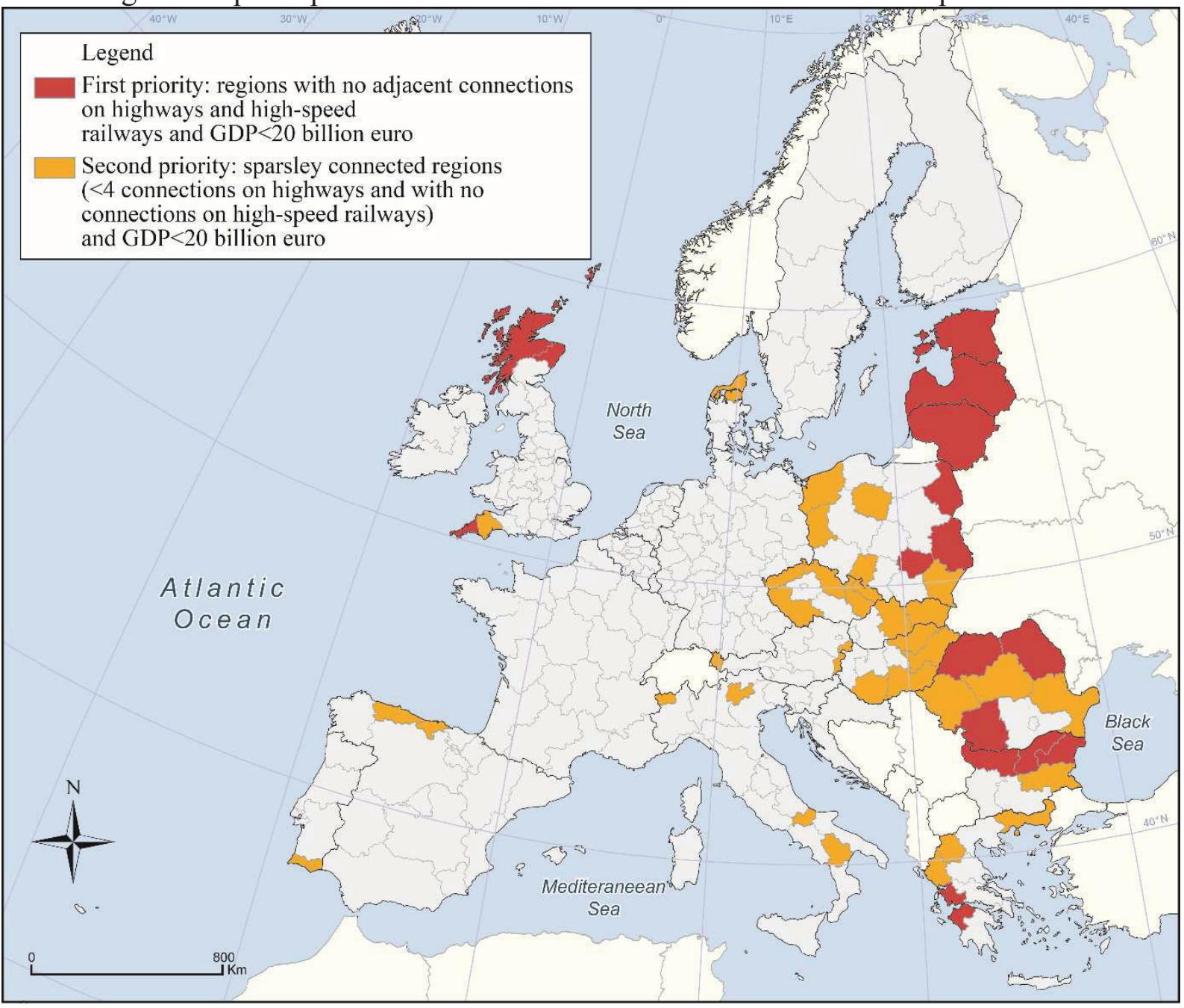

Source: Author's own representation

\section{CONCLUSIONS}

By reporting the degree of territorial interconnection to the economic potential defined by regional GDP, we quantified the impact of spatial accessibility on regional economic development in the EU. Based on the model we developed, we identified areas most vulnerable to isolation or poor accessibility, for which the improvement of interregional contact infrastructures could be a significant premise for regional economic growth.

In this context, we propose a two-level spatial hierarchy of territorial interconnection priorities, with a view on improving economic and territorial cohesion in the Union. The first priority for the expansion of transregional contact infrastructures is the regions with a regional GDP of less than EUR 20 billion and with no external links of highways and high-speed railways, and the second priority concerns regions with a regional GDP below EUR 20 billion and with external connections below the Community average. 


\section{REFERENCES}

[1] Humphreys, M. (2012), Sustainability in European Transport Policy, Routledge.

[2] Council of European Union (2006), Council Decision of 6 October 2006 on Community strategic guidelines on cohesion (2006/702/EC) - Annex, pt. 2.4, 2.5, 2.6, Brussels.

[3] Keeble, D., Owens, P. L., Thompson, C. (1982), Regional Accessibility and Economic Potential in the European Community, Regional Studies, 16(6), pp. 419-432.

[4] Krugman, P. (1991), Increasing returns and economic geography, Journal of Political Economy, 99(3), pp. 483-499.

[5] Fujita, M., Krugman, P. (2004), The new economic geography: Past, present and the future, Papers in Regional Science, vol. 83(1), pp. 139-164.

[6] Köhler, J. (2014), Globalization and Sustainable Development: Case Study on International Transport and Sustainable Development, The Journal of Environment \& Development, 23(1), pp. 66-100.

[7] Bertolini, L., Clercq, F., Kapoen, L. (2005), Sustainable accessibility: a conceptual framework to integrate transport and land use plan-making. Two test-applications in the Netherlands and a reflection on the way forward, Transport Policy, 12(3), pp. 207-220.

[8] Coppola, P., Papa, E. (2010), Accessibility Planning Tools for Sustainable and Integrated Land Use/Transport (LUT) Development: An Application to Rome, Procedia - Social and Behavioral Sciences, 87, pp. 133-146.

[9] Curtis, C., Scheurer, J. (2010), Planning for sustainable accessibility: Developing tools to aid discussion and decision-making, Progress in Planning, 74(2), pp. 53-106.

[10] Bueno, P. C., Vassallo, J. M., Cheung, K. (2015), Sustainability Assessment of Transport Infrastructure Projects: A Review of Existing Tools and Methods, Transport Reviews, 35(5), pp. 622-649.

[11] Hirschhausen, C. von (2002), Modernizing Infrastructure in Transformation Economies: Paving the Way to European Enlargement, Edward Elgar Publishing, Cheltenham.

[12] European Commission (2018), Transport in the European Union. Current Trends and Issues (retrieved from https://ec.europa.eu/transport/sites/transport/files/2018-transportin-the-eu-current-trends-and-issues.pdf).

[13] Hensher, D. A., Button, K. J., Haynes, K. E., Stopher, P. (2004), Handbook of Transport Geography and Spatial Systems, Series Handbooks in Transport, 5.

[14] Condeço-Melhorado, A., Reggiani, A., Gutierrez, J. (2014), Accessibility and Spatial Interaction, Edward Elgar Publishing, Cheltenham.

[15] Calatayud, A., Palacin, R., Mangan, J., Jackson, E., Ruiz-Rua, A. (2016), Understanding Connectivity to International Markets: a Systematic Review, Transport Reviews, 36(6), pp. 713-736.

[16] Condeço-Melhorado, A., Martin, J. C., Gutiérrez, J. (2011), Regional Spillovers of Transport Infrastructure Investment: A Territorial Cohesion Analysis, European Journal of Transport and Infrastructure Research, 11(4), pp. 389-404.

[17] Moreno, R., López-Bazo, E. (2007), Returns to Local and Transport Infrastructure under Regional Spillovers, International Regional Science Review, 30(1), pp. 47-71.

[18] Heshmati, A. (2013), Globalization and the E.U.'s Development Strategy, 1970-2007, Journal of Globalization Studies, 4(2), pp. 32-47.

[19] Godnič, B., Vodopivec, R. (2017), Globalization and Integration Processes in Europe, Journal of Universal Excellence, 6(1), pp. 1-10.

[20] Hae, K. (2013), Regionalism, Globalization and Economic Development of the World, Journal of Globalization Studies, 4(2), pp. 21-31. 
[21] Howell, A. (2013), Is Geography 'Dead' or 'Destiny' in a Globalizing World? A Network Analysis and Latent Space Modeling Approach of the World Trade Network, Journal of Globalization Studies, 4(2), pp. 3-20.

[22] Evers, D. (2008), Reflections on Territorial Cohesion and European Spatial Planning, Journal of Economic and Social Geography, 99(3), pp. 303-315.

[23] Panke, D. and Stapel, S. (2017), Overlapping regionalism in Europe: Patterns and effects, The British Journal of Politics and International Relations, 20(1), pp. 239-258.

[24] López, E., Gutiérrez, J., Gómez, G. (2008), Measuring Regional Cohesion Effects of Large-scale Transport Infrastructure Investments: An Accessibility Approach, European Planning Studies, vol. 16(2), pp. 277-301.

[25] Puga, D. (1999), The rise and fall of regional inequalities, European Economic Review, 43(2), pp. 303-334.

[26] Scholz, F. (2005), The Theory of Fragmenting Development, Geographische Rundschau, International Edition, 1(2), pp. 4-11.

[27] Baldwin, R., Forslid, R., Martin, P., Ottaviano, G., Robert-Nicoud, F. (2003), Economic Geography and Public Policy, Princeton University Press, Princeton.

[28] Berg, C. N., Deichmann, U., Liu, Y., Selod, H. (2017), Transport Policies and Development, The Journal of Development Studies, 53(4), pp. 465-480. 